\title{
Forced Convection upon Heat Sink of AL-Cu for Design Optimization by Experimental and CFD Analysis for Cooling of ICs in CPU
}

\author{
Srinivas. D, S. Ramamurthy, Juhi Ansari
}

\begin{abstract}
A heat sink device is used with specific power input at $100 \mathrm{~V}$ and $20 \mathrm{~W}$ by the heater attached at the base plate of copper and then obtaining the average temperature of Heat sink by the help of 10 thermocouples. .Two specimens of heat sinks were designed and were tested for mass flow rate and heat transfer coefficient. With base of 1.5mm\&2.5mmtip thickness and another specimen with dimensions as tip0.5mm and1.00mmbase thickness are used By experimenting and CFD simulations,optimization of heat sink design was done.Then correlation and Validation foe both the specimen was done and were found satisfactory results.
\end{abstract}

Keywords-Base plate,Cooling fan, CFD simulation, Heat sink, Heat dissipation, IC's ,Fin configuration, Thermocouples.

\section{INTRODUCTION}

In modern and recent advances in the science \& technology, especially in the electronics and computer application area a lot of advancements has taken place in Electronic cooling in CPU. Also with advent, few drawbacks are also seen in operations \& application of electronic cooling in CPU. Recent advances using with compact space for computers, heat dissipation from IC's has been a complex phenomenon. Hence by using easy design \& fabrication, experimental calculations and by simulation we can overcome the problems. Software simulations correlation was done for better design and performance of the heat sinks. As stated earlier, these metal foams not only possess desirable properties of the bulk metal such as corrosion resistance, acceptance of coatings, and high electrical and thermal conductivity, but also qualities such as a low density, high strength-to-weight ratio, high porosity, and extremely large surface-area-to-volume ratio. Wirtz et al. (1994) [1] experimentally studied the effect of flow bypass on longitudinal fin heat sinks. They evaluated inter-fin velocity from measured values of fin heat transfer coefficients and used these results to derive a correlation for inter-fin velocity in terms of Reynolds number as a function of the free stream Reynolds number and fin density. Yuan et al. (1996)[2] studied flow bypass effects on straight fin heat sinks in a rectangular duct by computational fluid dynamics modelling.

Revised Manuscript Received on December 30, 2019.

* Correspondence Author

Srinivas. D, Prof and Head mechanical engg,Research Scholar,JAIN,Bengaluru.

S. Ramamurthy, 2Prof at R\&D,CMET,JAIN,Bengaluru,

Juhi Ansari, Asst prof,E\&C,KCT Engg college,kalaburagi\&Research scholarVTU,Belagavi,Karnataka..

(C) The Authors. Published by Blue Eyes Intelligence Engineering and Sciences Publication (BEIESP). This is an open access article under the CC BY-NC-ND license (http://creativecommons.org/licenses/by-nc-nd/4.0/)
The computational model accuracy was verified by excellent agreement with experimental data of a test problem. Simons and Schmidt (1997) [3]proposed a simple hydrodynamic model to predict the inter-fin velocity of a plate fin heat sink by applying mass and momentum balances between fins and bypass area by considering negligible pressure drop in the bypass area, without showing their procedure to calculate pressure drop inside the heat sink. Sinks may vary significantly as far as the design, material or the fins are concerned. However, they are chosen in order to suit the usage of each system. A lot of systems use a forced flow regime due to the fact that quite fast cooling of the electronic devices is needed. Sultan, [4]; R Mohan and P Govindarajan,[6],springer,journal of mechanical science and technology,\&KSME.

\section{EXPERIMENTAL SETUP AND PROCEDURE}

The material for fins or Extended surfaces used are a combination of Aluminium as fins and Copper as base plate material. Two specimens were prepared with tapered fins of Aluminum \& base plate material of copper. One specimen ofdimensions $40 \mathrm{~mm} \times 50 \mathrm{~mm} \times 5 \mathrm{~mm}$ and second specimen with dimension of $40 \times 50 \times 2.0 \mathrm{~mm}$ is prepared. A small heater is attached at the base of copper plate . Both the materials have been machined carefully for the required dimensions.Silicon compound and adhesivegel are used to attach the fins to the base plate. Aluminum tapered fins in 4 numbers are fixed to the copper plate.The two specimens with fins of base thickness $2.5 \mathrm{~mm} \&$ tip thickness $1.5 \mathrm{~mm}$.and $1 \mathrm{~mm}$ base and $05 \mathrm{~mm}$ tip thickness of fins respectively fixed. To regulate the heat a centrifugal blower is fixed above the fins horizontally with flow rate of 90 CFM, with radius of fan diameter $90 \mathrm{~mm}$. The temperatures are measured on heat sink by ten(10) $\mathrm{J}$ type of thermocouples. The position of thermocouples are at $10 \mathrm{~mm}$ from the base of fin on heat sink, Each fin consist of two thermocouples, overall thermocouples are 08 on fins.The copper base plate is fixed with 02 thermocouples at centre to measure the base plate temperature. Hence, a total of 10 thermocouples are fixed on the heat sink. Heat is supplied to the heat sink heater with constant power of 20W, with steady state and even assumed that the change in maximum temperature was minimum than $\pm 10^{\circ} \mathrm{C}$ for a time span of 4minutes.A voltmeter, wattmeter \& temperature indicator were connected to measure the required parameters. Steady temperature of $50^{\circ} \mathrm{C}$ for heat sink is obtained with surrounding temperature as $38^{\circ} \mathrm{C}$. 
Both the specimen are as shown below in figure-1a\&b.and the dimensions used are given in table $1 \& 2$.

Figure 1: Heat sink specimen (a) Without holes (b) With holes

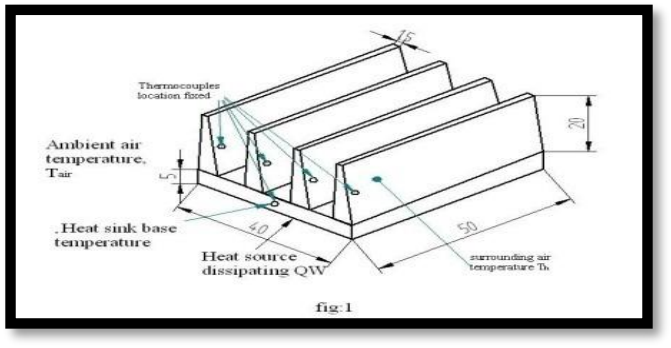

fig1(a)

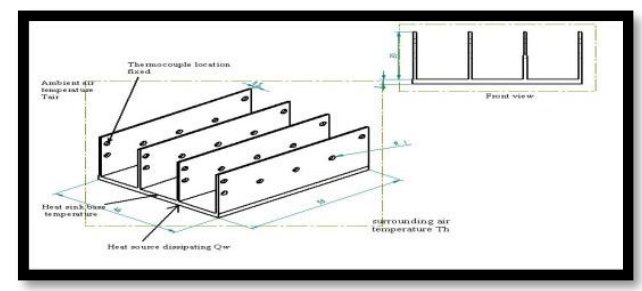

Fig 1 (b)

Table1:Dimensions of the heat sink with holes

\begin{tabular}{|c|c|c|}
\hline $\begin{array}{c}\text { Fin Length, } \\
\mathbf{L}_{\mathrm{f}} \\
(\mathrm{mm})\end{array}$ & $\begin{array}{c}\text { Fin Height } \\
\mathbf{H}_{\mathbf{f}} \\
(\mathbf{m m})\end{array}$ & $\begin{array}{c}\text { Fin } \\
\text { Width } \\
\text { W }_{\mathrm{f}} \\
\text { mm }\end{array}$ \\
\hline 50 & 20 & 40 \\
\hline $\begin{array}{c}\text { Fin } \\
\text { Number } \\
\mathbf{N}\end{array}$ & $\begin{array}{c}\text { Thickness } \\
\text { of fin at tip } \\
\mathbf{t}_{\mathrm{ft}} \\
(\mathrm{mm})\end{array}$ & $\begin{array}{c}\text { Fin -to- Fin } \\
\text { distance } \xi \\
(\mathrm{mm})\end{array}$ \\
\hline 04 & 0.5 & 15 \\
\hline $\begin{array}{c}\text { Base } \\
\text { thickness } \\
\mathbf{t}_{\mathrm{b}} \\
(\mathrm{mm})\end{array}$ & $\begin{array}{c}\text { Base Fin } \\
\text { Thickness } \\
\mathrm{t}_{\mathrm{fb}} \\
(\mathrm{mm})\end{array}$ & $\begin{array}{c}\text { Holes On } \\
\text { Sinks } \\
\text { mm }\end{array}$ \\
\hline 2.0 & 1 & $\begin{array}{l}\text { of } 2 \mathrm{~mm} \\
\text { diameter }\end{array}$ \\
\hline
\end{tabular}

Table 2:Dimensions of the heat sink without holes

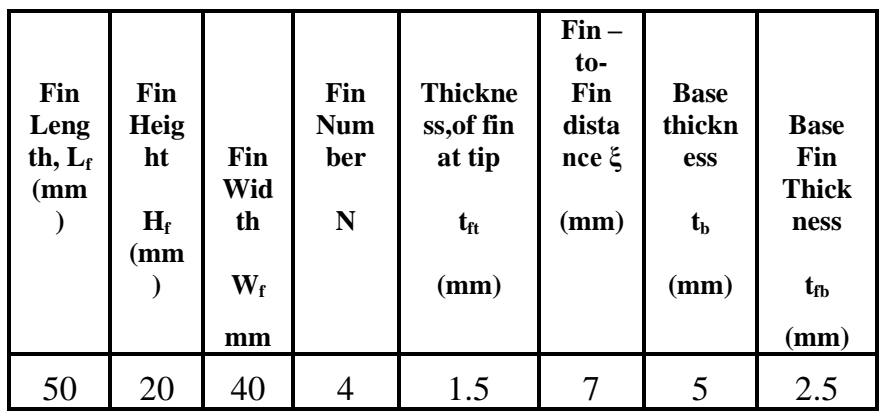

Table-3: comparison of experimental and analytical values obtained during this research work.

\begin{tabular}{|c|c|c|c|c|}
\hline \multirow{2}{*}{$\begin{array}{c}\text { Fin } \\
\begin{array}{c}\text { Configurati } \\
\text { on }\end{array} \\
\end{array}$} & \multicolumn{2}{|c|}{ Mass flow rate $(\mathrm{kg} / \mathrm{s})$} & \multicolumn{2}{|c|}{$\begin{array}{l}\text { Heat transfer co- } \\
\text { efficient }\left(W / \mathbf{m}^{2} K\right)\end{array}$} \\
\hline & $\begin{array}{c}\text { Experimen } \\
\text { tal }\end{array}$ & $\begin{array}{c}\begin{array}{c}\text { Analytic } \\
\text { al }\end{array} \\
\end{array}$ & $\begin{array}{c}\text { Experimen } \\
\text { tal }\end{array}$ & $\begin{array}{c}\begin{array}{c}\text { Analytic } \\
\text { al }\end{array} \\
\end{array}$ \\
\hline $\begin{array}{l}\text { Without } \\
\text { Holes }\end{array}$ & 0.0495 & 0.0492 & 22.7698 & 22.086 \\
\hline $\begin{array}{l}\text { With } 8 \\
\text { Holes } \\
\end{array}$ & 0.0495 & 0.0493 & 22.7702 & 21.859 \\
\hline $\begin{array}{l}\text { With } 12 \\
\text { Holes }\end{array}$ & 0.0495 & 0.04926 & 22.7745 & 22.319 \\
\hline $\begin{array}{l}\text { With } 16 \\
\text { Holes }\end{array}$ & 0.0495 & 0.04917 & 22.7812 & 21.642 \\
\hline
\end{tabular}

\subsection{CFD ANALYSIS:}

\section{Table:3}

CFD analysis of the experimental setup was conducted as per the conditions used in the experimentation. The heat sink model and the fluid domain was generated using CATIA V5 which was exported to the Fluent component in the ANSYS solver. The inlet velocity was calculated from the fan flow rate and the temperature of the heat sink was kept at a steady $50^{\circ} \mathrm{C}$. The analysis was performed for four models as given below.

a) Heat sink without holes

b) Heat sink with 8 holes

c) Heat sink with 12 holes

d) Heat sink with 16 holes

After the analysis, the three models with holes were compared to get one with the best performance. The velocity profile obtained from CFD analysis of the specimen are as shown in Figure 2.

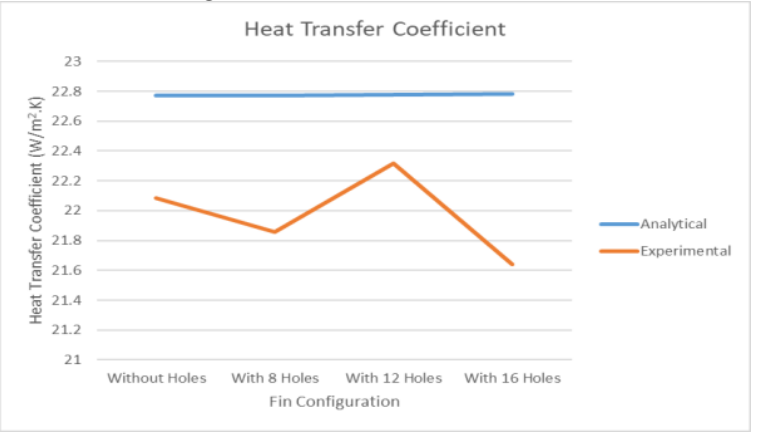

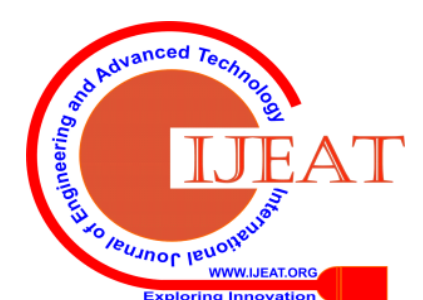



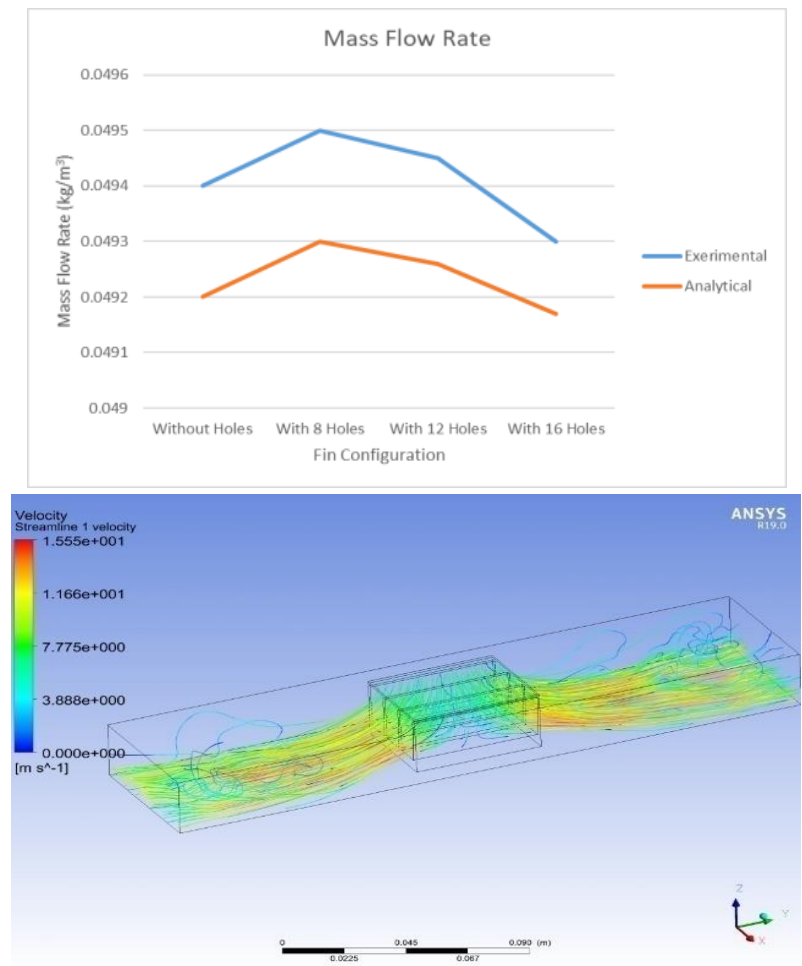

(b)

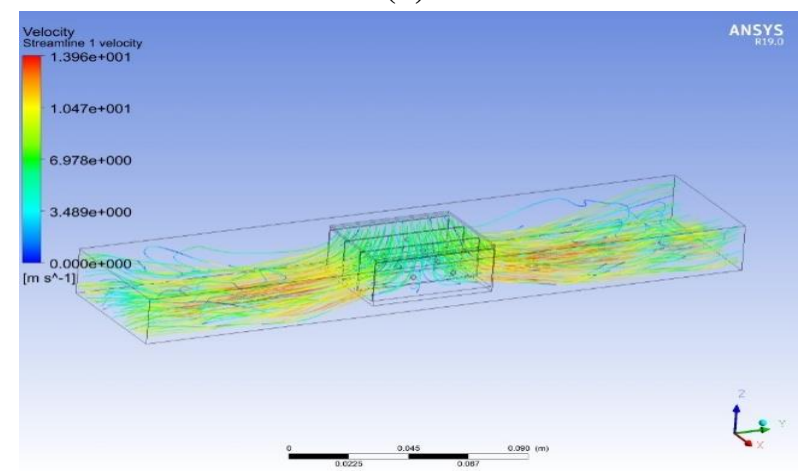

(c)

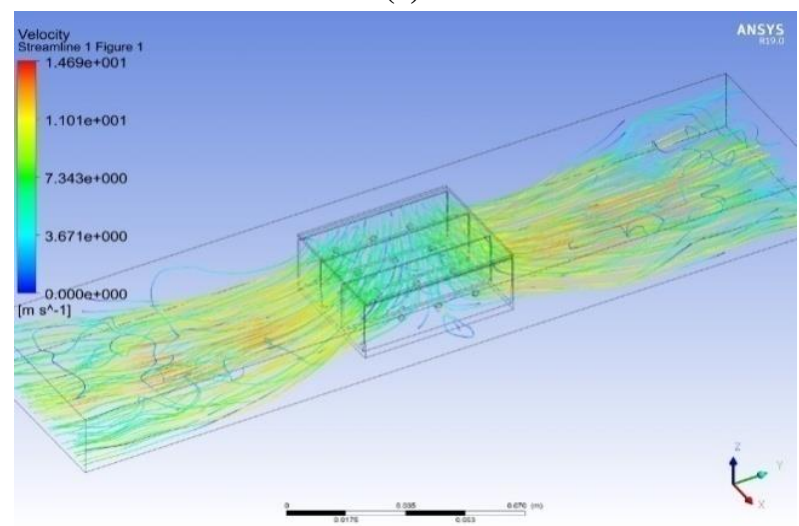

(d)

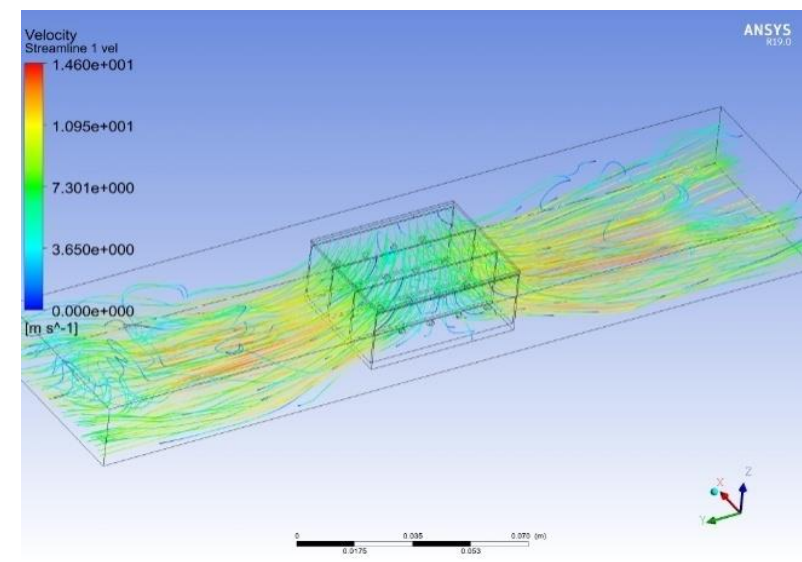

Figure 2: Velocity Profile of the heat sink (a) without holes (b) with 8 holes (c) with 12 holes (d) with 16 hole

CFD ANALYSIS OF ALL FOUR SPECIMENS SHOWING.

HEAT TRANSFER COEFFICENTS a]without holes

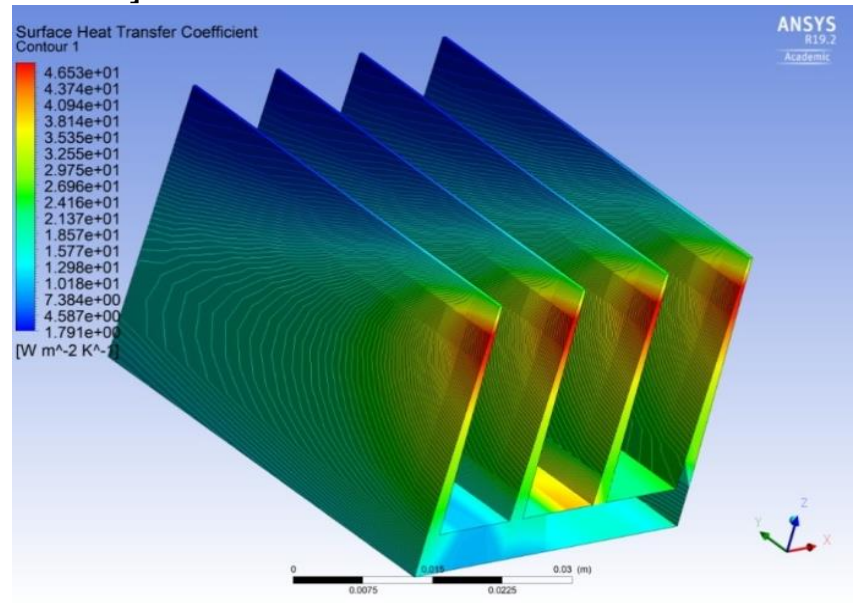

b] with 8 holes

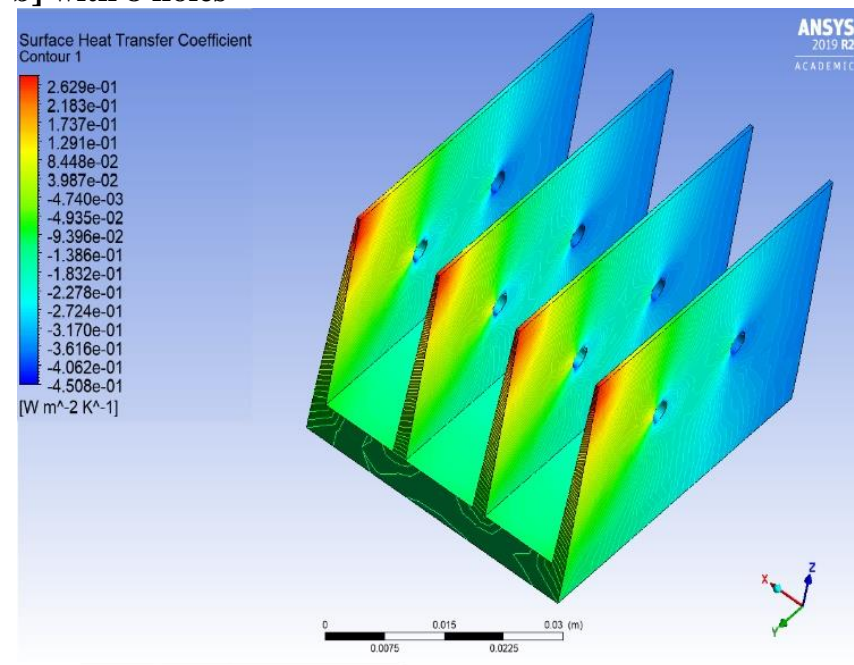

c] with 12 holes

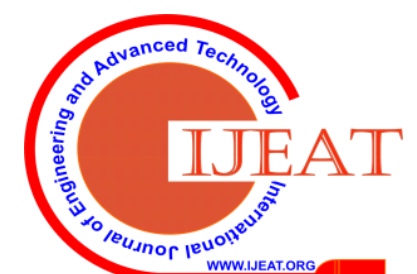


Forced Convection upon Heat Sink of AL-Cu for Design Optimization By Experimental and CFD analysis for cooling of ICs in CPU

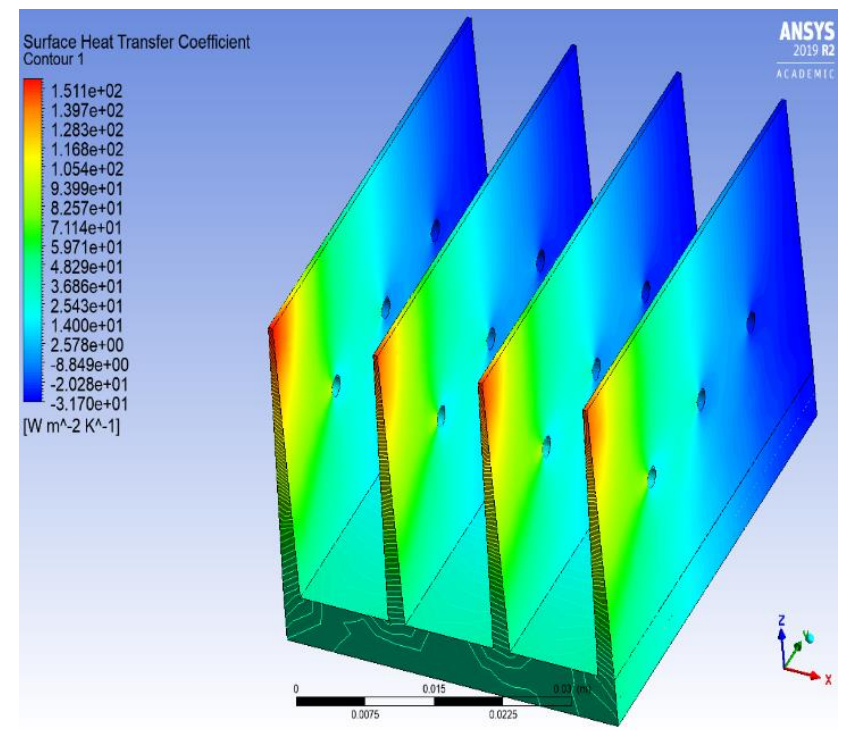

\section{B] WITH 8 HOLES}

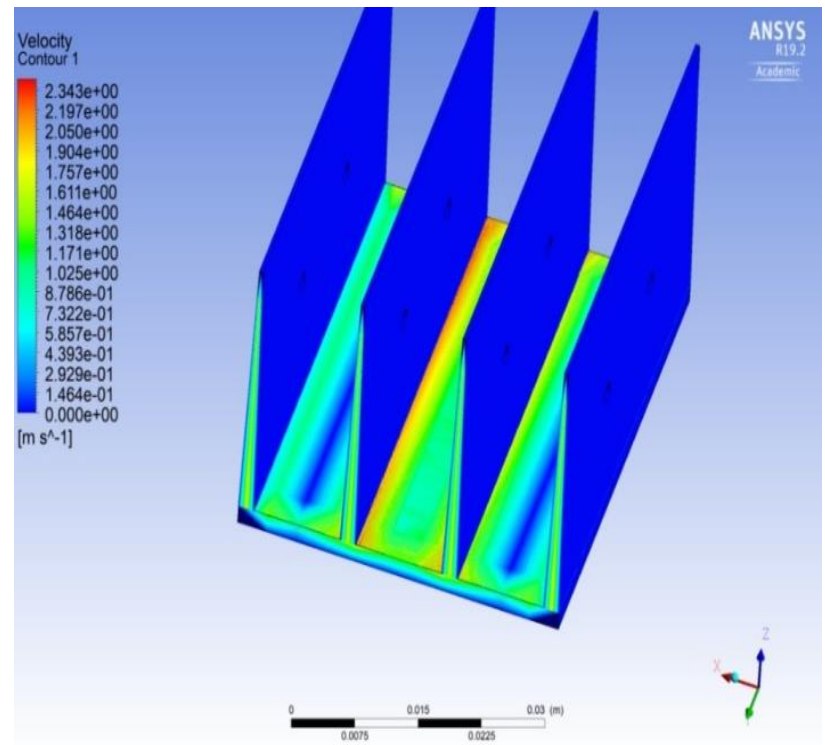

\section{d] with 16 holes}

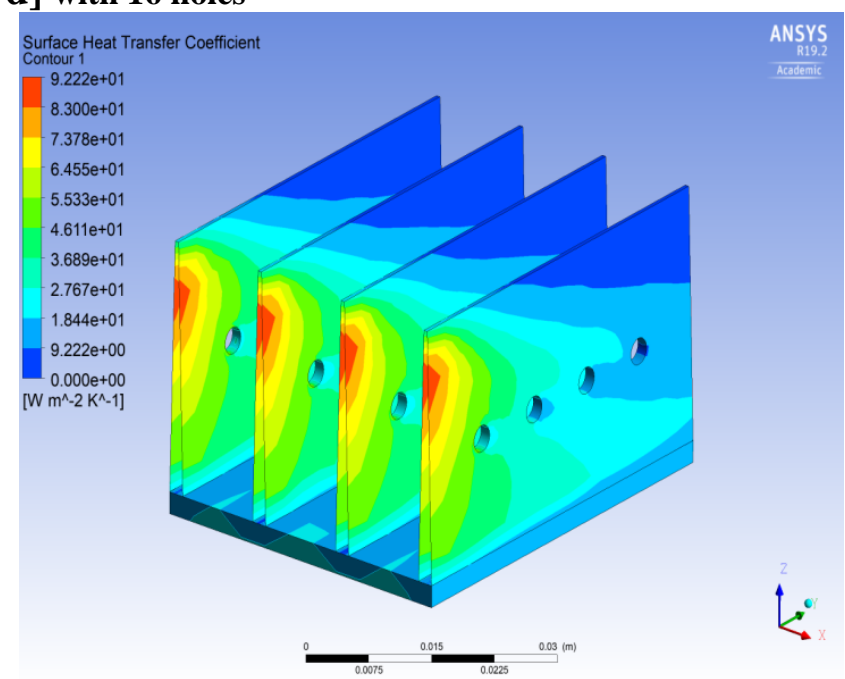

CFD VELOCITY PROFILES OF ALL HEAT SINKS

A] WITHOUT HOLES.

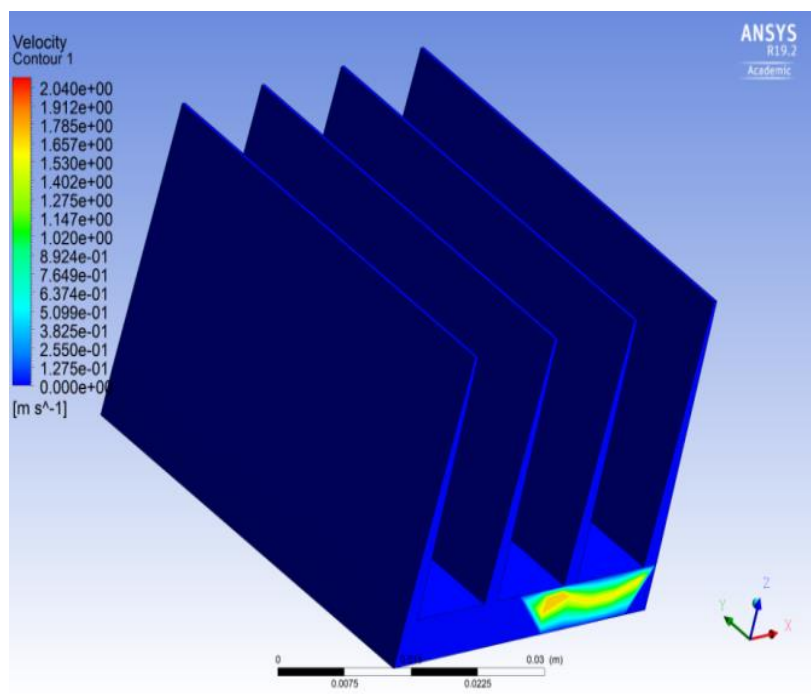

Retrieval Number: A9867109119/2019@BEIESP

\section{D] WITH 16 HOLES}

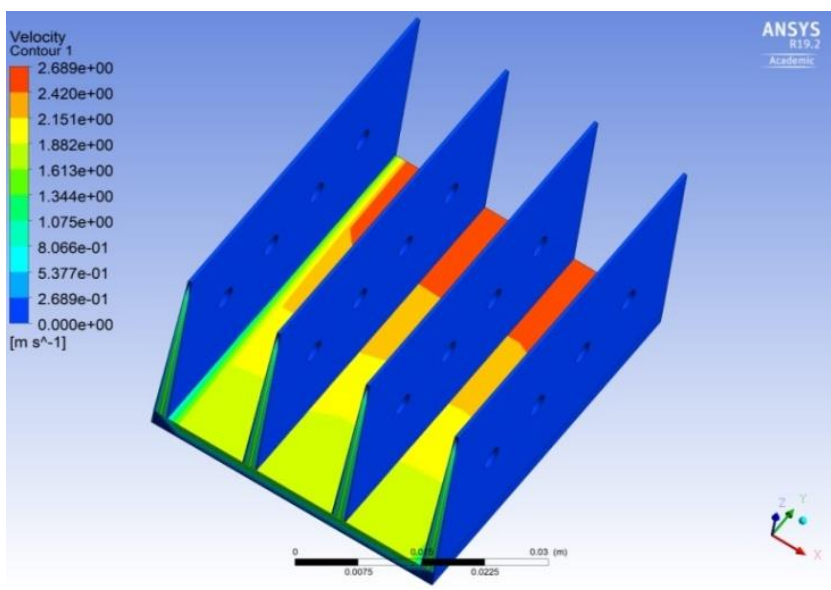

VELOCITY PROFILES CURVES OF ALL HEAT SINKS. 


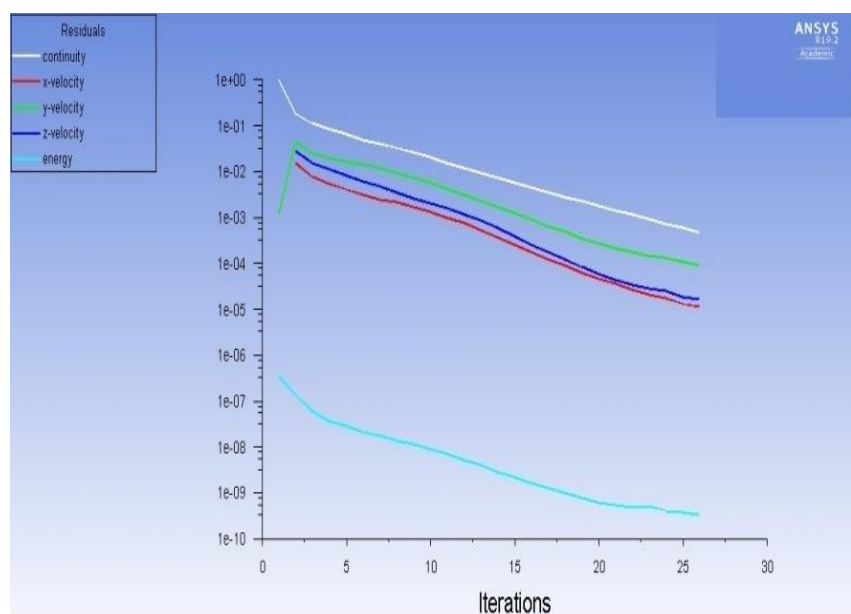

A] WITHOUT HOLES

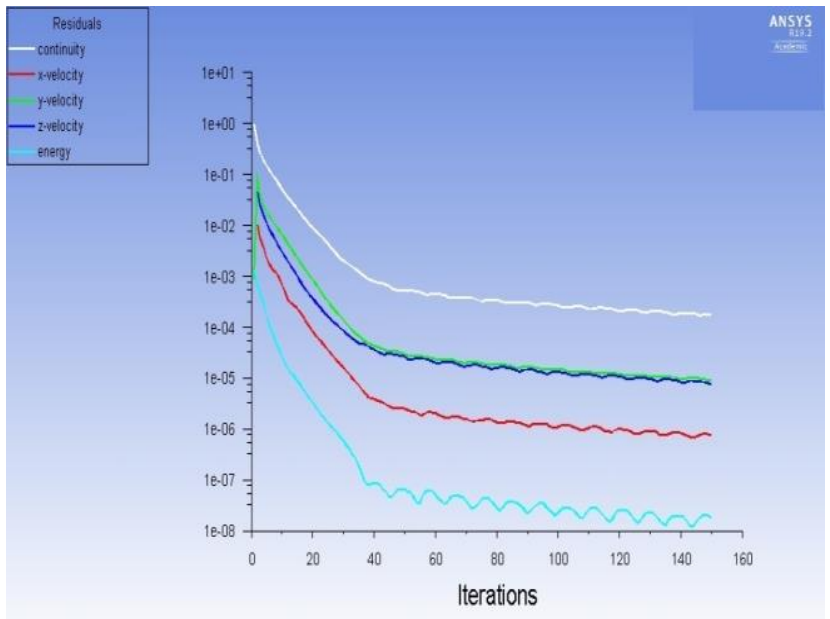

B] WITH 8 HOLES

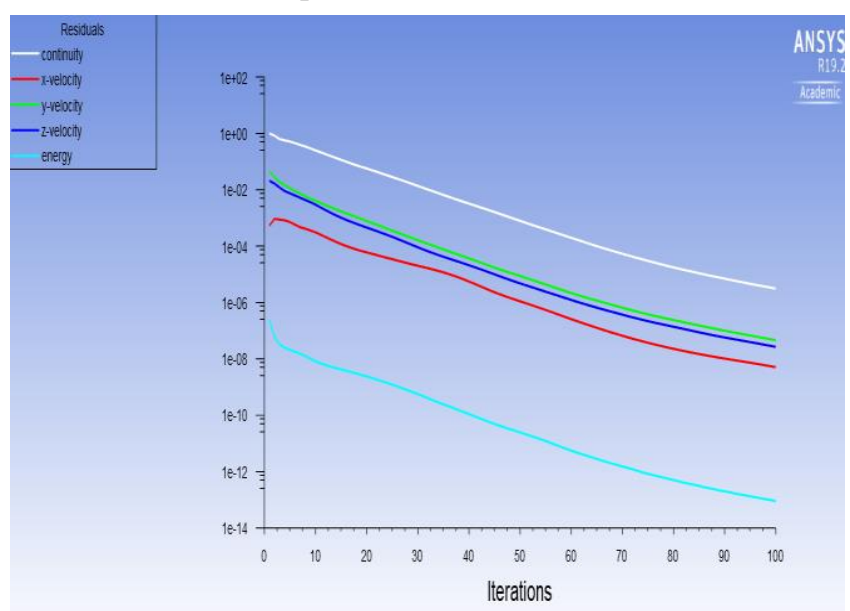

C] WITH 12 HOLES

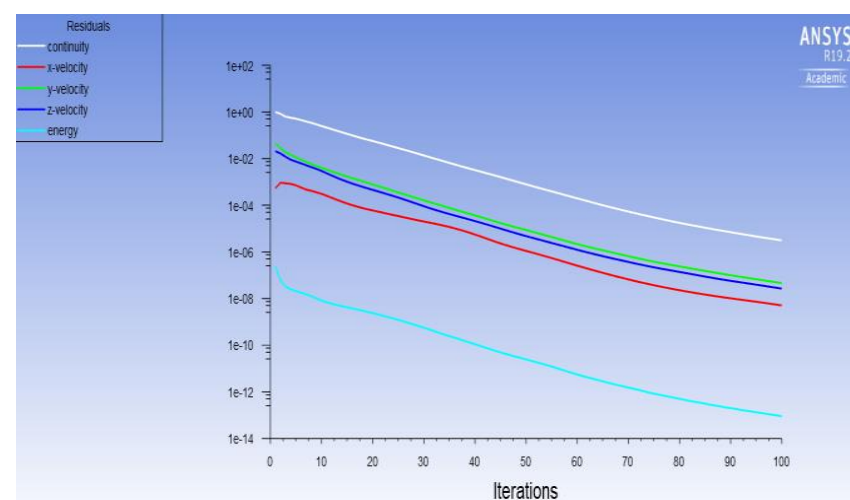

D] WITH 16 HOLES

\section{CONCLUSIONS}

The main focus of this research work is to compare the heat transfer between heat sinks of different configurations. This was achieved by comparing four different configurations i.e., Heat sinks without holes, with 8 holes, with 12 holes and with 16 holes. The heat transfer co-efficient obtained through experimentation and CFD analysis indicated that the theoretical model selected for analysis was similar to the experimental model and the values are in close agreement with each other with a very small difference between 11.5\%.FINALLY HEAT SINK WITH 12 HOLES WAS SEEN AS OPTIMUM VALUE.

\section{REFERENCES.}

1. Wirtzet al. (1994)S.Lee,(1995),optimum design and selection of heat sink, IEEE semi thermo symposium.experimentally studied the effect of flow bypass on longitudinal fin heat sinks.

2. Yuan et al. (1996) studied flow bypass effects on straight fin heat sinks in a rectangular duct by computational fluid dynamics modelling.

3. Simons and Schmidt (1997) proposed a simple hydrodynamic model to predict the inter-fin velocity of a plate fin heat sink by applying mass

4. Sultan, 2.Rodgers and Eveloy (2003) indicated that computational fluid dynamics software can be a great tool to substantially predict the temperature distribution, A lot of systems use a forced flow regime due to the fact that quite fast cooling of the electronic devices is needed.

5. Leon et al. (2004), who solved the numerical equations with the implementation of ANSYS FLUENT program.Optimum heat sink Design and Selection at IJIAEM,2013

6. RMohan andGovindarajan,2011)springer, journalof mechanical science technology,\&KSME

7. Shashank Deorah "CFD Analysis of a vertical tube having internal fins for the Natural

8. Yu et al. performed concluded that thermal resistance of plate-fin heat sinks is lower by approximately $30 \%$ than that of pin fin heat sinks with the same blowing velocity.

\section{AUTHORS PROFILE}

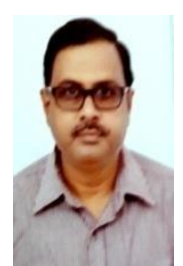

Srinivas.D. is Prof and HOD-mechanical engineering,inreputedengineeringcollege,in Karnataka.He isResearch Scholar at JAIN(deemed tobeuniversity).Bangalore.Karnataka.Also member of American Society of Mechanical engineering.(ASME),NY,USA. Also member of professional bodies in India,MIE,ISTE.I was a top contributor at ASME. Hestudied,BE(mech),ME(TPE),in reputed engineering college PDACE,Kalaburgi in karnataka.Ihave totally nearly 25yrs of Teaching experience in Engineering colleges and 05yrs in Industry. 